\title{
Analisis Model Bisnis pada UMKM Kuliner yang Menerapkan Konsep Sharing Food
}

\author{
Vitha Octavanny \\ Institut Komunikasi dan Bisnis LSPR, Bekasi, Indonesia
}

\begin{abstract}
ABSTRAK
Penelitian ini bertujuan untuk merancang Business Model Canvas (BMC) yang telah dijalankan pada Bisnis Kuliner Pitiks Roast Chicken. Metode penelitian yang digunakan adalah deskriptif dengan pendekatan kualitatif. Pengumpulan data yang dilakukan menggunakan teknik wawancara. Temuan penelitian menunjukkan bahwa di masa pandemi ini bisnis kuliner dapat dijalankan secara digital. Keberadaan tempat makan dine-in menjadi faktor yang kurang penting. Temuan lain menunjukkan bahwa value proposition yang menjadi keunggulan Pitiks Roast Chiken ini adalah konsep sharing food yang bergaya Internasional dengan cita rasa tradisional. Hasil analisis SWOT menghasilkan rekomendasi yang mana diperlukan metode baru untuk memperluas pangsa pasar dengan berbagai perancangan yang matang dengan cara menjalin kerjasama dengan beberapa platform online untuk meningkatkan revenue dan penelitian ini menilai Pitiks perlu mensosialisasikan value yang dimiliki kepada masyarakat sehingga awareness dapat terbangun di benak masyarakat sebagai makanan sharing.
\end{abstract}

Kata kunci : Business Model Canvas; Analisis SWOT ; Bisnis Kuliner Pitiks

\section{BUSINESS MODEL DESIGN USING THE BUSINESS MODEL CANVAS APPROACH: A STUDY ON CULINARY BUSINESS PITIK ROAST CHICKEN}

\begin{abstract}
This study aims to design a Business Model Canvas (BMC) which has been implemented in the Pitiks Roast Chicken Culinary Business. The research method used is descriptive with a qualitative approach. Data collection was carried out using interview techniques. Research findings show that during this pandemic, culinary businesses can be run digitally. The existence of a dine-in place is a less important factor. Another finding shows that the value proposition that is the advantage of Pitiks Roast Chicken is the concept of sharing food with an international style with traditional flavors. The results of the SWOT analysis produce recommendations in which new methods are needed to expand market share with various mature designs by cooperating with several online platforms to increase revenue and researchers also assess that Pitiks needs to socialize its values to the community so that awareness can be built in the minds of the people as sharing food.
\end{abstract}

Keywords: Business Model Canvas; SWOT Analysis; Pitiks Culinary Business 


\section{PENDAHULUAN}

Tahun 2020, menjadi tahun yang penuh tantangan bagi pelaku bisnis kuliner karena pandemi Covid-19 membuat perilaku masyarakat berubah. Kebiasaan makan di luar yang sudah menjadi gaya hidup berubah, masyarakat saat ini lebih memilih memasak dan menyantap makanan di rumah bersama keluarga. Demikian pula, kebijakan work from home membuat para pekerja makan siang di rumah. Bagi karyawan yang masih bekerja di kantor, kebiasaan makan siang di restoran atau rumah makan di sekitar kantor menjadi berubah dengan membawa bekal makan siang dari rumah. Kebijakan pemerintah seperti Pembatasan Sosial Berskala Besar (PSBB) membuat restoran dan rumah makan tidak dapat membuka tempat usaha kulinernya. Kondisi ini tentu saja membuat para pelaku bisnis kuliner melakukan inovasi agar bisa tetap mempertahankan usaha bisnisnya dalam keadaan yang terbatas. Salah satu caranya dengan membangun bisnis kuliner yang memiliki online store, maka dengan itu setiap bisnis kuliner perlu mengulas kembali strategi bisnis mereka dengan stategi dan metode yang baru sehingga dapat menjadi solusi bagi para konsumen saat ini.

Badan Pusat Statistik (Husjakarsih et al., 2020) melaporkan penjualan online di Indonesia pada periode Februari hingga Juli 2020 meningkat tajam. Berdasarkan total transaksi penjualan online, kategori produk favorit masyarakat adalah bahan makanan sebanyak 51 persen, disusul oleh produk kesehatan yang mencapai 20 persen dan selanjutnya di posisi ketiga adalah kebutuhan pulsa atau paket data sebesar 14 persen. Kondisi ini menunjukkan bahwa dalam masa pandemi ini dan berada di rumah lebih lama membuat masyarakat memilih untuk membeli bahan makanan melalui daring.

Bisnis kuliner adalah salah satu dari 15 subsektor ekonomi kreatif. Bisnis kuliner merupakan bagian dari industri penyedia makanan yang kegiatannya meliputi semua hal yang terkait dengan aktivitas memasak yang mana estetika dan kreativitas merupakan elemen yang sangat penting. Segmen industri ini meliputi restoran lokal, restoran full-service, toko makanan, dan jasa boga. Kementerian Perindustrian memprediksi industri makanan pada tahun 2021 dapat bertumbuh hingga 4,49 persen (Arief, 2021). Hal ini menunjukkan optimis dari pemerintah karena program vaksinasi sudah berjalan dan masyarakat dan para pelaku bisnis kuliner sudah mulai sadar akan protokol kesehatan.

Dominan usaha bisnis kuliner di Indonesia berbentuk Usaha Mikro Kecil Menengah (UMKM). Menurut Ketua Umum Kamar Dagang dan Industri Jawa Timur, UMKM di sektor kuliner masih cukup mampu bertahan di masa pandemi ini. Tak dipungkiri banyak UMKM Kuliner yang mengalami penurunan omzet. Namun pada saat yang bersamaan, banyak pula pelaku UMKM kuliner baru yang bermunculan (Ginanjar, 2021). Hal ini menunjukkan bahwa bisnis kuliner masih merupakan bisnis yang berpotensi menguntungkan dan makanan dan minuman merupakan kebutuhan primer manusia. Faktor yang penting bagi bisnis kuliner, khususnya dimasa pandemi ini adalah inovasi dan bagaimana strategi pemasaran yang dilakukan sehingga produk kuliner yang ditawarkan kepada masyarakat sesuai dengan kebutuhan dan cita rasa pasar sasaran yang dituju,

Para pelaku bisnis kuliner harus menciptakan inovasi baru dan menciptakan strategi pemasaran yang dapat membuat usaha kuliner yang dibangun memiliki ciri khas yang menjadi keunggulan dalam bersaing dengan para kompetitor. Selain itu, usaha bisnis harus memiliki dasar model bisnis yang baik dan kuat sebagai wujud pemikiran dari pengusaha tentang bagaimana suatu organisasi menciptakan, memberikan, dan menangkap nilai produk yang akan ditawarkan kepada konsumen (Osterwalder \& Pigneur, 2010). Sebuah model bisnis 
memiliki sembilan elemen yang menjadi cetak biru bagi organisasi untuk menjalankan usaha bisnisnya dengan efektif. Melalui sembilan kunci utama ini perusahaan dapat melihat kelebihan dan kelemahan dari model bisnis yang dimiliki (Jackson \& Harjanti, 2015). Oleh karena itu, Business Model Canvas akan memudahkan perusahaan maupun UMKM Kuliner untuk mengevaluasi kembali aktivitas yang sudah dilakukan dan menemukan aktivitas baru yang dapat dilakukan untuk mengembangkan bisnisnya.

Guna mengembangkan Business Model Canvas agar semakin efektif maka dilakukan analisis SWOT yang merupakan teknik sederhana namun terbukti mampu dan tepat untuk mengukur kekuatan sumber daya organisasi dan kekurangan, peluang pasarnya, dan ancaman eksternal terhadap masa depannya (Dergisi, 2017). Selain itu juga analisis SWOT akan membantu mengidentifikasi kerangka perencanaan strategis yang digunakan dalam evaluasi organisasi, rencana, proyek atau kegiatan bisnis.

Salah satu UMKM kuliner yang menarik untuk dikaji adalah Pitiks Roast Chicken. Berawal dari garasi rumah di daerah Duren Sawit, Jakarta Timur, Pitiks Roast Chicken merupakan bisnis kuliner berbahan dasar utama ayam yang didirikan oleh kakak dan beradik Mohamad Syawal Syawie dan Mohamad Hilman Syawie. Salah satu pemilik yaitu Mohamad Syawal Syawie yang masih berada di usia yang relatif muda 29 tahun dengan berbagai pengalaman kerja di dunia kuliner di luar maupun dalam negeri mendirikan usaha kuliner dengan konsep share food untuk membawa kebersamaan dalam menikmati makanan dengan keluarga atau kerabat. Selain itu, Pitiks Roast Chicken juga menyediakan makanan yang bebas MSG, pengawet, pewarna buatan,perasa buatan, dan aditif lainnya dengan bahan produk ayam. Meskipun makanan disajikan terkesan Internasional, namun Pitiks Roast Chicken tetap menonjolkan cita rasa tradisional dengan menggunakan rempah rempah khas Indonesia.

Tradisi makan bersama dianggap menjadi salah satu ekspresi budaya yang dapat di tonjolkan, menurut (Hayden, 2014) dapat diartikan sebagai communal consumption (feasting) atau communal meal dengan definisi, "any sharing between two or more people of special foods in a meal for a special purpose occasion atau dapat diartikan suatu kebiasaan makan bersama dapat disebut dengan berbagi makanan, di sisi lain, manusia dapat berbagi makanan dengan orang orang yang memiliki hubungan langsung atau memiliki kedekatan yang tidak biasa, dalam hal ini menjadi keunikan tersendiri dalam membangun konsep share food dengan membawa suasana kebersamaan dalam menyantap hidangan yang disajikan oleh Pitiks Roast Chicken dengan orang-orang special .

Konsep dan nilai produk kuliner yang ditawarkan oleh Pitiks Roast Chicken menarik untuk ditelaah lebih detail dengan model bisnis Canvas untuk mengetahui sembilan elemen yang menjadi pertimbangan utama Pitiks Roast Chicken dapat mengembangkan bisnis kuliner. Selain itu, dengan bermunculan kuliner sejenis menjadikan Pitiks Roast Chicken memerlukan evaluasi terhadap model bisnis yang telah diterapkan agar semakin efektif dan semakin kuat menonjolkan ciri khas yang merupakan keunggulannya dibanding dengan para kompetitor.

\section{Literature Review}

Osterwalder \& Pigneur (2010) mendeskripsikan pembuatan perencanaan bisnis dengan melalui sembilan kunci utama yang dijabarkan melalui sembilan blok dasar untuk dapat membantu sebuah usaha maupun organisasi untuk dapat menghasilkan nilai jual maupun peningkatan profit dari apa yang disusun dalam Business Model Canvas ini. Sembilan kunci 
utama terdiri dari 1) Customer Segments: yaitu kegiatan menentukan konsumen yang menjadi sasaran pasar dari usaha bisnis yang akan dikembangkan. Kelompok konsumen mana yang akan menjadi pelanggan dan bagaimana karakteristik mereka. Bagaimana opini, gaya hidup dan sikap mereka sehingga produk atau jasa yang ditawarkan sesuai dengan kebutuhannya; 2) Value Proposition yaitu identifikasi value (nilai) yang mampu memenuhi kebutuhan pelanggan. Nilai yang ditawarkan juga harus memiliki keunggulan dan ciri khas yang menjadi pembeda dengan nilai yang ditawarkan oleh pesaing; 3) Channels adalah cara untuk menghantarkan nilai kepada pelanggan. Bagaimana nilai yang ditawarkan oleh perusahaan dapat diterima dan dirasakan dengan baik oleh pelanggan; 4) Customer Relationship: yaitu menggambarkan hubungan antara perusahaan dan pelanggan. Berbagai cara dapat diterapkan untuk membangun hubungan yang baik dengan pelanggan, seperti memberikan bantuan personal kepada setiap pelanggan, atau dapat juga dengan memanfaatkan komunitas, dan di masa pandemi ini 'self-service' menjadi pilihan yang tepat karena tidak berhubungan secara langsung dengan pelanggan; 5) Revenue Streams yaitu pendapatan berupa uang yang akan diterima dari setiap pembelian yang dilakukan oleh pelanggan; 6) Key Activities: adalah kegiatan utama dan penting yang dilakukan perusahaan dalam menciptakan produk atau jasa; 7) Key Resources: adalah sumber daya utama yang menjadi aset terpenting yang diperlukan dalam menjalankan suatu usaha bisnis; 8) Key Partnership: adalah kunci kemitraan yang menjelaskan jaringan pemasok dan mitra yang membuat pekerjaan model bisnis. Perusahaan menjalin kemitraan untuk berbagai alasan, dan kemitraan menjadi landasan model bisnis. Terdapat empat jenis kemitraa yaitu strategi aliansi antara non pesaing, strategi kemitraan antara pesaing (Competition), usaha bersama: usaha untuk mengembangkan bisnis baru, Hubungan Pembeli-Pemasok untuk menjamin pasokan yang dapat diandalkan (Zulkifar, 2019) dan 9) Cost Structure adalah struktur biaya yang menggambarkan semua biaya yang dikeluarkan dalam menjalankan usaha bisnis.

\section{Model Bisnis di Industri Kuliner}

Disampaikan dalam Buku Rencana Pengembangan Kuliner Nasional 2015-2019 (Lazuardi \& Triady, 2015). Bahwasanya makanan menjadi bahan dasar kebutuhan manusia yang perlu di penuhi maka itu makanan pasti akan menjadi hal yang terus dicari dengan berbagai macam rasa dan tampilan yang berbeda, dengan hal tersebut bisnis kuliner akan menjadi solusi yang tidak akan pernah padam bagi masyarakat mupun investor. Bisnis kuliner unik akan selalu berkembang seiring waktu. Saat ini mungkin sudah hampir ribuan jenis usaha kuliner unik yang sudah banyak dijalankan dan bisa ditemukan di sekitar.

Beragamnya usaha kuliner unik ini sebenarnya tidak lepas dari rasa ingin tahu manusia terhadap hal baru. Dengan itu terdapat model bisnis kuliner yang saat ini dapat dijadikan acuan menjalankan bisnis, yaitu: a) Independent adalah bentuk model bisnis yang dibangun oleh perorangan maupun kumpulan kelompok dengan berfokus pada satu area tertentu. Usaha jenis ini juga mengharuskan pemiliknya untuk bertanggung jawab dalam seluruh alur kerja yang terjadi dalam setiap proses usahanya. Mayoritas usaha Food and Beverage atau rumah makan yang sejenis ini akan mempunyai seorang juru masak yang sudah memiliki pengalaman sehingga berminat untuk memiliki bisnis kuliner pribadi. b) Chain: bentuk model bisnis Chain ini adalah bentuk bisnis yang biasanya dikelola dengan sekelompok pengusaha maupun perusahaan yang mendirikan beberapa bisnis yang sudah disebarkan di berbagai tempat dengan menggunakan satu merek yang sama. c) Franchise: Bentuk model bisnis ini hampir setipe dengan bentuk bisnis chain, namun saja pemilik dari setiap bisnisnya ini dapat berbeda kepemilikanya, dengan cara pembeli merek mendapatkan hak untuk dapat 
menjualkan bisnis tersebut. Secara definisinya bahwa franchise atau waralaba terikat Peraturan Pemerintah No. 31 Tahun 2008 yaitu peraturan ketika disalah satu pihak mendapatkan hak untuk memanfaatkan dan/atau menggunakan Hak dari Kekayaan Intelektual (HKI) atau kekhasan dalam usaha yang dimiliki pihak satunya dalam imbalan dengan persyaratan yang sudah ditentukan oleh pihak lain tersebut dalam rangka penyediaan dan atau penjualan barang dan jasa.

Pada kesempatan ini Pitiks Roast Chicken memilih untuk memulai bisnis kuliner independent dengan memanfaatkan kemampuan dan pengetahuan di bidang kuliner, tetapi model bisnis Independent ini tidak menutup kemungkinan akan dapat merambah model bisnis lainya seperti Franchise.

\section{METODE PENELITIAN}

Penelitian ini menggunakan pendekatan kualitatif dengan jenis penelitian deskriptif. Analisis yang digunakan adalah business model canvas dan analisis SWOT yang merupakan sebuah metode untuk mengoptimalkan antara kekuatan dan peluang guna mengurangi kelemahan dan ancaman yang dapat membantu untuk memformulasikan strategi yang tepat bagi perusahaan untuk berkembang (Bateman \& Snell, 2009, p. 149). Kaitan analisis SWOT dengan Business Model Canvas (BMC) yaitu membantu untuk mengidentifikasi kekuatan dan kelemahan, serta peluang dan ancaman yang dihadapi oleh perusahaan dalam proses implementasi sembilan elemen BMC. Kombinasi analisis SWOT dan BMC memungkinkan penilaian yang terfokus berdasarkan evaluasi kemampuan perusahaan dan kemungkinan pengembangan bisnis Pitiks Roast Chicken di masa depan.

Metode penelitian yang digunakan adalah metode studi kasus. Menurut Yona (2006) metode studi kasus merupakan metode yang melakukan penyelidikan mendalam sehingga dapat mengetahui secara lengkap gambaran keadaan perusahaan tersebut. Tujuan dari studi kasus yaitu dapat mengantarkan peneliti untuk memasuki unit-unit sosial seperti individu, kelompok, lembaga atau komunitas

Subjek dalam penelitian kali ini adalah individu yang terlibat dalam pengelolaan usaha bisnis yaitu pemilik kuliner Pitiks Roast Chicken. Sedangkan objek penelitian ini adalah merancang model bisnis Kuliner Pitiks Roast Chicken dengan menggunakan pendekatan 9 elemen dalam business model canvas yaitu customer segments, value propositions, channels, customer relationships, revenue streams, key sources, key activities, key partnerships, dan cost structure.

Data primer adalah data yang diperoleh secara langsung dari sumber data dengan observasi langsung (Sugiyono, 2014). Sedangkan data primer menurut Kuncoro (2009, p. 145) ialah data yang di dapat lalu dikumpulkan dari sumber-sumber asli untuk tujuan tertentu. Menurut Sanusi (2012), data primer dalam penelitian ini diperoleh dari hasil wawancara dan identifikasi sembilan elemen business model canvas pada Bisnis Kuliner Pitiks Roast Chicken dengan itu dapat disimpulkan bahwa data primer ini data untuk mengidentifikasi hal tertentu dengan cara mengobservasi langsung dari sumber sumber terpercaya atau asli.

Teknik pengumpulan data yang digunakan dalam penelitian ini adalah wawancara. Menurut 
Yusuf (2014), wawancara merupakan suatu proses interaksi antara pewawancara (interviewer) dan sumber informasi atau orang yang diwawancarai (interviewee) melalui komunikasi langsung. Wawancara merupakan kegiatan yang bertujuan untuk memperoleh informasi secara mendalam dan detail tentang sebuah masalah yang akan dijawab dalam penelitian.

Teknik wawancara yang digunakan dalam mendapatkan data primer adalah wawancara in depth interview. Beberapa pertanyaan yang telah dipersiapkan ditanyakan kepada narasumber, namun membuka kemungkinan pertanyaan lain muncul seiring jawaban yang diberikan oleh narasumber. Hal ini dikarenakan wawancara bertujuan untuk mendapatkan bukti atau jawaban dari masalah penelitian secara terbuka, detil dan konsisten.

\section{Teknik Analisis Data}

Pendekatan Kualitatif memiliki tiga tahapan teknik menganalisis data yaitu : Data Reduction yang mana tahapan tersebut mampu memfokuskan untuk meringkas informasi atau data penting, hal tersebut dapat bertujuan untuk membuat sebuah alur maupun topik sehingga data tersebut mampu memperjelas dan memudahkan suatu penelitian dalam melakukan analisis data yang terstruktur sesuai kebutuhan peneliti; tahapan kedua adalah Data Display yaitu data berupa grafik, diagram hingga tabel yang mana tujuanya dapat memudahkan dalam membaca data; dan tahapan ketiga adalah Conclusion Drawing/Verification adalah tahapan akhir penarikan sebuah kesimpulan dan memverifikasi yang diikuti oleh data pendukung seperti bukti yang tepat, apabila bukti tersebut tidak tepat dan tidak terstruktur maka peneliti dapat melakukan penelitian lapangan kembali untuk mencari data sehingga menghasilkan kesimpulan yang terpercaya, tahapan tersebut di sampaikan oleh Sugiono (2016).

\section{HASIL DAN PEMBAHASAN}

\section{Profil Pitiks Roast Chicken}

Pitiks memiliki 3 Produk menu main course yaitu Pitiks Family Box dengan harga Rp 198.0oo, menu kedua Pitiks Leg dengan harga Rp 65.00o dan menu terakhir Pitiks Parmigiana dengan harga Rp 55.00o, Pitiks Roast Chicken ini juga memiliki cara untuk mempromosikan produknya dengan memberikan diskon $5 \%$ untuk pembelian minimal 10 boxes. Produk yang ditawarkan dengan berbahan dasar ayam ini memiliki rasa pedas dengan berbagai pelengkap sauce yang tawarkan seperti chimmicurri cita rasa wangi dan gurih, ada pula hot fermented cita rasa pedas dan asam dan yang terakhir barbeque sauce.

Pitiks memiliki jam pengiriman yang sudah dibagi menjadi 2 sesi yaitu pukul 11.00 dan 16.00 WIB dengan pemesan 1 hari sebelumnya atau maksimum pesanan 10 jam sebelumnya karena sistem preorder yang dilakukan oleh Pitiks.

\section{Gambar 1. Logo Pitiks}

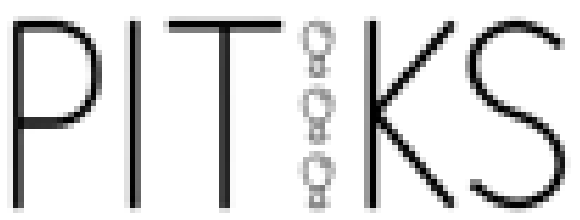




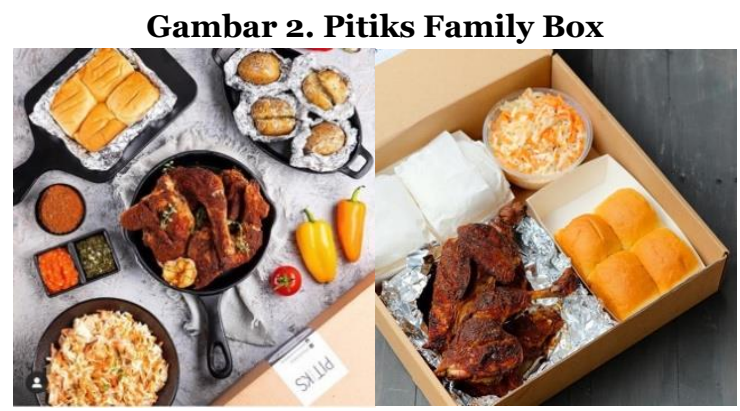

Sumber: Instagram Pitiks Roast Chicken (2021)

Gambar 3. Pitiks Parmigiana

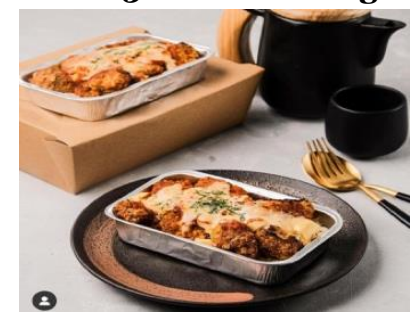

Sumber: Instagram Pitiks Roast Chicken (2021)

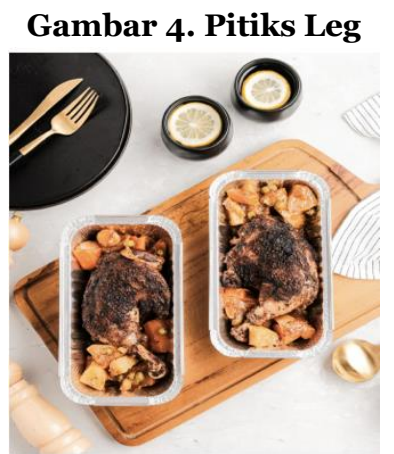

Sumber: Instagram Pitiks Roast Chicken (2021)

\section{Business Model Canvas}

Segmentasi konsumen dari Pitiks Roast Chicken ini adalah orang-orang yang sedang berkumpul dengan keluarga maupun area perkantoran dengan konsentrasi terhadap makanan-makanan yang sehat karena pengolahan produk Pitiks ini menggunakan sedikit sekali minyak dan proses pengolahanya tidak digoreng melainkan dipanggang, selain itu juga Pitiks menargetkan pasar bagi masyarakat masyarakat yang menginginkan makanan praktis untuk dinikmati, Pitiks pun menyediakan peralatan makanan dalam pendistribusian seperti piring plastik maupun sarung tangan untuk memudahkan konsumen menikmati makananya di mana saja.

Kendalanya dalam segmentasi pasar adalah konsumen yang memesan dengan kekhususan ayam seperti ayam pejantan karena kali ini Pitiks hanya menyediakan ayam broiler dan saat ini Pitiks masih belum bergabung dengan platform digital seperti GoFood, GrabFood karena saat ini sajian yang dilakukan oleh Pitiks adalah preorder system dan sistem yang tersedia dalam platform tersebut tidak menyediakan konsep preorder. Selama menjalani usaha ini Pitiks menyarankan pengiriman instan untuk dapat menjaga kualitas pada produk yang disediakan dengan itu pengiriman paling jauh saat ini area Bandung itupun dengan sistem 
jasa titip. Pengelola Pitiks masih dalam proses riset bagaimana cara untuk menjangkau lokasi yang lebih luas dengan tidak mengurangi cita rasa yang diharapkan oleh Pitiks ini.

Pitiks Roast Chicken mengandalkan konsep Sharing Food menjadi value proposition yang mampu diingat oleh pelanggan di saat mereka membutuhkan makanan sharing. Apabila melihat dari lokasi store Pitiks ini tidak sulit untuk dijangkau dan Pitiks ini selain menjual makanan roast chicken, mereka menawarkan sistem pengantaran tetapi banyak dari konsumen menggunakan sistem platform sebagai cara pendistribusiannya. Di saat pandemi ini Pitiks Roast Chicken belum merasa membutuhkan konsep dine-in dalam usahanya memang dari awal usaha, pemilik tidak terpikir untuk membuat usaha dine-in. Bisnis kuliner berbasis digital ini akan menjadi pilihan tepat bagi UMKM kuliner di tengah masa pandemi untuk dapat menekan biaya operasional dan fokus pada nilai produk yang lain.

Pitiks Roast Chicken saat ini masih memfokuskan Instagram dan WhatsApp dalam proses pemesanan, sebelumnya pernah menggunakan marketplace Tokopedia untuk proses distribusinya (Channel) tetapi masih memiliki kendala karena platform yang beragam dengan sumber daya manusia yang masih belum memadai sehingga terdapat gap internal dalam proses distribusinya.

Pitiks Roast Chicken belum mengarahkan ke investasi store secara offline mengingat akan banyak modal yang akan keluar dibandingkan pemesan melalui online, dengan sistem pendistribusian seperti itu Pitiks merasa perlu meningkatkan tampilan yang menarik dalam online store-nya, yang mana saat ini adalah Instagram maka Pitiks menggunakan fotografer profesional yang menghasilkan foto makanan yang dapat menarik awareness maupun dorongan untuk melakukan pembelian.

Pitiks Roast Chicken memiliki 3 personil dalam menjalankan bisnisnya, 2 orang fokus terhadap operasional termasuk pendirinya dan 1 orang yang mana adik dari pemilik Pitiks menjadi bagian keuangan. Proses pengiriman yang dilakukan oleh Pitiks lebih dari 3 boxes masih dapat menggunakan kendaraan bermotor tetapi apabila pesanan melebihi dari 3 boxes Pitiks menyarankan menggunakan kendaraan roda empat agar kualitas saat diterima masih baik.

Pitiks Roast Chicken memiliki cara sendiri dalam menjalin hubungan dengan konsumen (Customer Relationship) dengan cara rutin menanyakan saran dari konsumen dan mereka melakukan hal tersebut di 1 tahun pertama untuk mengetahui kekurangan mayoritas dari konsumen, setelah 1 tahun berjalan Pitiks hanya menanyakan secara random kepada konsumen di saat makananya tersebut sudah sampai dan bagaimana kondisi makanan tersebut, selain dengan cara mengevaluasi makanan yang diberikan Pitiks pun memberikan hadiah cookies kepada konsumen yang sudah melakukan transaksi berulang selama 6 bulan.

Sebelum pandemi, pemiliki Pitiks Roast Chicken ini telah dahulu menjalankan bisnis rice box catering, buffet, serta penerimaan pesanan untuk makanan ulang tahun atau acara acara keluarga dengan kapasitas 40 sampai dengan 100 pax tetapi selama pandemi bisnis tersebut terhenti sejenak untuk pemesanan katering. Selang 6 bulan berjalan membuka Pitiks pemilikipun sering membuka Open Preorder untuk makanan makanan Hainan Chicken rice, Bibimbap, Salmon Mentai, Chicken Gyros maupun makanan nusantara yang mana 
makanan tersebut diluar dari konsep Pitiks atau sharing food dengan begitu sebenarnya pemilik ini memiliki 2 income atau revenue, pertama penjualan murni Pitiks Roasted Chicken dan membukan preorder makanan Asia lainya yang menjadi pendapatan bisnis kuliner ini.

Pitiks Roast Chicken yang bermula dari garasi rumah pribadi menjadi sebuah bisnis kuliner yang dapat menjanjikan memanfaatkan lahan kosong di area rumah menjadi salah satu strategi yang dilakukan Pitiks untuk terhindar dari biaya sewa dalam proses bisnisnya dan hal tersebut sangat menguntungkan bagi pebisnis ini, karena menyewa tempat menjadi biaya yang perlu dipersiapkan setiap periodenya.

Saat ini sumber daya manusia yang tergabung dalam proses bisnis kuliner ini ada 3 orang yang mana 2 dari tim tersebut adalah kakak beradik sebagai pendiri Pitiks Kuliner ini dan satu personil lagi adalah karyawan. Pitiks Roast Chicken masih merencanakan pembuatan logo dan mematenkan nama dari Pitiks sendiri hanya saja masih dalam rencana. Selain logo dan nama yang menjadi keunggulan Pitiks ini memiliki bumbu rahasia yang tidak diketahui orang lain dari hasil pengalaman bekerja di berbagai tempat kuliner di dalam maupun luar negeri.

Selain catering dan pengolahan makanan kurang lebih 5 jam aktivitas yang dilakukan saat ini, Pitiks mulai berani mengikuti kompetisi kompetisi kuliner dan kompetisi pertama yang dilakukan adalah "Culinary Entrepreneur Awarding" yang diselenggarakan oleh LSPR Communication and Business Institute dan Pitiks berhasil menjadi juara kelima, mulai saat itu Pitiks mulai merasa percaya diri untuk mengikuti kompetisi kompetisi lain kedepanya.

Pitiks ini sudah menggunakan sosial media sebagai cara mempromosikan bisnis kuliner yang telah dijalani seperti paid promotion dan juga menggunakan jasa selebgram atau endorse saat diawal berjalanya bisnis tetapi tidak begitu efisien saat kami menggunakan jasa endorse, selain itu Pitiks pernah mensponsori salah satu club bola lokal dan logo Pitiks di tampilkan pada kaos yang mereka gunakan.

Pitiks Roast Chicken masih belum memiliki supplier sebagai key partnership yang tetap karena ayam sendiri rasanya dapat mudah ditemukan di mana-mana dan saat ini kapasitas pemesanan per harinya masih di tahap wajar untuk didapatkan di supplier secara acak dan bumbu yang digunakan pun masih mudah ditemukan, dan saat ini pembukaan franchise maupun reseller masih dalam proses perencanaan bagaimana konsep yang akan ditawarkan kepada mitra.

Terakhir, terkait cost structure, yaitu hasil keuntungan dikembalikan untuk modal usaha, promosi, giveaway, sponshorship hingga gaji karyawan. Keuntungan bisnis Pitiks Roast Chicken ini adalah usaha yang memanfaatkan area rumah sehingga biaya sewa tempat tidak di masukan kedalam biaya fixed cost perusahaan.

\section{Analisis SWOT}

Analisis SWOT dilakukan untuk mengevaluasi rancangan model bisnis kanvas Pitiks Roast Chicken yang telah dijalankan guna mengoptimalkan kekuatan dan peluang serta meminimalkan kelemahan dan ancaman. Hasil akhir dari analisis SWOT ini adalah dapat 
mengembangkan model bisnis yang lebih baik agar usaha bisnis mampu bertahan di masa depan.

\section{Customer Segmentation}

Pitiks memiliki kekuatan (strength) dalam customer segmentation ialah bahan makanan yang mudah diterima di masyarakat luas dan menargetkan keluarga maupun perkantoran, lokasi tidak jauh dari pusat perkantoran menguntungkan pebisnis selain itu tren hidup sehat juga menjadi salah satu kekuatan Pitiks untuk menarik pasar yang menginginkan makanan sehat atau less calorie, namun kelemahan Pitiks (weakness) belum bisa menjangkau cakupan pasar di luar Jabodetabek dan penggunaan platform digital yang terbatas. Tetapi dengan kelemahan itu terdapat kesempatan (opportunities) yaitu usaha kuliner saat ini sedang digandrungi oleh banyak orang ditambah lagi situasi pandemi saat ini yang membatasi aktivitas makan di luar menjadi kesempatan Pitiks untuk mengambil peluang ini. Threats: bisnis kuliner yang semakin kompetitif dengan banyaknya jenis makanan kuliner yang beragam hingga kompetitor yang sejenis bermunculan saat pandemi.

\section{Value Propotition}

Kekuatan (strengths) Value Propotition yang dimiliki Pitiks ialah konsep yang unik dan menjadikan konsep sharing food sebagai value proposition dalam bisnis kulinernya, Namun adanya kekurangan (weakness) belum memiliki visi misi dan hanya mengandalkan media sosial Instagram dan Whatsapp saja dalam proses penjualan maupun sosialisasi brand tetapi Pitiks memiliki cara dalam membuat nilai kepada pada konsumenya yang tertera dalam komponen peluang (opportunities) bisnis kuliner rumahan atau UMKM sedang meningkat maka akan dengan mudah memperkenalkan makanan sharing food ini ke masayarat. Adapun ancaman (threats) yang perlu diwaspadai ialah nilai yang ditawarkan masih belum tersosialisasikan dan bersaing sehingga belum cukup untuk membuat calon konsumen tertarik.

\section{Channel}

Kekuatan (strength) Channel yang dimiliki Pitiks ialah dengan mengunakan tenaga profesional dalam pengambilan gambar produce, sehingga membuat online store menjadi jauh lebih menarik tetapi kelemahan (weakness) yang dimilik belum memaksimalkan platform maupun social media yang beragam dan belum bisa menjangkau wilayah di luar Jabodetabek, selain itu juga dengan sistem preorder yang membuat konsumen tidak bisa membelinya saat itu juga. Namun peluang (opportunity) Pitiks dapat memanfaatkan media online untuk penjualan produk karena saat ini penggunaaan media digital saat ini sangat menguntungkan dibandingkan harus menyewa ruangan saat pandemi ini. Hanya saja perlu juga diperhatihan ancaman (threat) yaitu pasar yang terbatas hanya untuk konsumen online saja dan pengiriman harus menggunakan kendaraan roda empat apabila pengiriman melebihi 3 boxes sehingga ongkos kirim yang perlu ditanggung konsumen akan jauh lebih besar.

\section{Customer Relationship}

Kekuatan (strength) dalam elemen Customer Relationship ialah Pitiks melakukan riset dengan menayakan saran kepada konsumen dan memberikan hadiah kepada konsumen yang sudah melakukan transaksi berulang selama 6 bulan dan memiliki hubungan yang baik dengan konsumen, namun kelemahan (weakness) yang dimiliki dari segi pelayanan saran ini masih dilakukan oleh pemilik yang merangkap sebagai chef maupun admin media sosial. 
Adapun peluang (opportunity) Pitiks ialah akan banyak mendapatkan saran maupun ide-ide segar dari konsumen sehingga menjadikan Pitiks jauh lebih berkembang sesuai dengan kebutuhan yang diinginkan konsumen salah satunya saran ragam karbohidrat dan sambal yang perlu ditambahkan. Selain itu, adapun ancaman (threat) ialah kemampuan kompetitor yang sudah menyediakan pelayanan yang lebih siap dibandingkan Pitiks seperti sistem ready-to-eat di berbagai platform yang tersedia. Selain itu dengan adanya perkembangan teknologi yang pesat sehingga juga dapat memudahkan penyebaran informasi negatif karena ketidakpuasan konsumen.

\section{Revenue Stream}

Kekuatan (strength) Revenue Stream yang didapat oleh Pitiks ialah memiliki revenue selain di Pitiks Rosted Chicken, namun kelemahan (weakness) Pitiks pemesanan hanya menggunakan Instagram dan WhatsApp saja dan pembayaran hanya menggunakan via transfer. Tetapi terdapat peluang (opportunity) yaitu keahlian dari pemilik sendiri tidak hanya dapat membuat makanan Roast Chicken saja tetapi dapat membuat makanan selain itu sesuai kebutuhan konsumen sehingga menjadi peluang yang baik untuk meningkatkan pendapatan bagi Pitiks sendiri. Perubahan tren untuk parcel saat hari raya Idul Fitri maupun Natal tidak hanya terbatas pada makanan-makanan kering, saat ini pengiriman parcel maupun hampers dapat menggunakan makanan basah dan hal ini menjadi peluang untuk menaikkan revenue Pitiks ini, namun adanya ancaman (threat) yaitu terhentinya sejenak usaha katering karena pandemi sehingga pengurangan terhadap revenue.

\section{Key Resource}

Kekuatan (strength) dalam key resource adalah memiliki bumbu rahasia yang menjadi aset besar untuk Pitiks selain itu pula Pitiks memiliki chef yang berpengalaman dalam dunia kuliner di dalam maupun luar negeri tetapi terdapat kelemahan (weakness) saat ini masih belum mendaftarkan logo maupun nama bisnis usaha kepada Dirjen Hak Kekayaan Intelektual (HKI). Adapun peluang (opportunity) yang dimiliki Pitiks ialah tidak terganggunya pengeluaran dari biaya sewa tempat karena tempat yang digunakan adalah garasi rumah pribadi. Tetapi apabila Pitisk tidak segera mendaftarkan nama bisnisnya akan menimbulkan ancaman (threat) karena nama maupun logo bisa digunakan oleh siapa saja selama belum terdaftar HKI.

\section{Key activities}

Kekuatan (strength) yang dimiliki Pitiks adalah riset yang dilakukan oleh Pitiks mampu menjawab kebutuhan dari konsumen, Pitiks juga melakukan sponsorship kepada club sepak bola lokal dan kali ini juga Pitiks sudah memulai mengkikuti kompetisi kompetisi kewirausahaan untuk memperluas jaringan bisnisnya, selain itu pembagian tugas sudah tersampaikan dengan jelas, namun adanya kekurangan (weakness) yang dimiliki seperti belum masuk UMKM daerah maupun komunitas bisnis kuliner sehingga informasi informasi tentang usaha bisnis kuliner masih minim seperti terdapat potongan pendaftaran HKI apabila menjadi bagian dari UMKM daerah atau informasi-informasi kompetisi. Peluang (opportunity) yang dapat dimanfaatkan saat ini ialah Era digital ini memudahkan promosi seperti paid promotion maupun sponsorship. Digital activity dapat digunakan untuk memperbesar peluang pemanfaatan aktivitas Pitiks tetapi meskipun digital dapat memudahkan kegiatan promosi adakalanya ancaman (threat) yang perlu diantisipasi ialah penggunaan sistem endorse belum menjamin kefektifitasan penjualan 


\section{Key Partnership}

Kekuatan (strength) Pitiks dalam menjalin Kerjasama dengan mitra ialah sudah menjalin kerjasama dan memberikan sponsorship kepada club bola lokal , namun adanya kelemahan (weakness) perlunya menambah kerjasama dengan bergabung ke komunitas bisnis kuliner maupun UMKM dan menetapkan supplier tetap agar tidak menghasilkan harga yang berbeda-beda, sedangkan peluangnya (opportunity) yaitu bahan dasar yang digunakan cukup mudah ditemukan, kesempatan unuk memperluas bisnis kuliner dengan menggaet reseller selain itu dapat membuka peluang menjadi supplier pada bisnis-bisnis kuliner lainnya seperti Business-to-Business, memasukan Roasted Chicken ini menjadi salah satu komoditas makanan di salah satu bisnis kuliner lainnya. Ancaman (threat) yang akan dihadapi oleh Pitiks adalah kompetitor yang sudah memiliki sistem reseller maupun sudah jauh lebih stabil dari segi branding.

\section{Cost Structure}

Kekuatan (strength) biaya fixed cost tidak terlalu banyak, dan biaya fixed dan variable cost dapat diperhitungkan sebelumnya, namun kekurangannya (weakness) dikarenakan Pitiks adalah bisnis yang dijalankan di rumah dengan itu biaya pribadi dan biaya operasional tidak terpisahkan. Tetapi Pitiks memiliki peluang (opportunity) meminimalisir biaya yang tidak diperlukan seperti sewa tempat dan memanfaatkan area rumah menjadi tempat bisnis dan ancamannya (threat) inflasi membuat biaya menjadi ikut naik

\section{SIMPULAN}

Kesimpulan yang dapat diambil dalam penelitian ini dilihat dari berbagai indikator 9 elemen model business canvas sebagai berikut Customer Segment: Pitiks Rosted Chicken menjalani bisnis kuliner pada tahun 2019 dengan segmentasi pasar family dan perkantoran yang menyukai makanan sehat. Value Propostition: Pitiks Rosted Chicken memiliki konsep sharing food dengan gaya internasional dengan berbagai rempah Indonesia. Lokasi Pitiks Roast Chicken terletak di lokasi yang yang tidak sulit untuk dicapai. Channel: Pitiks hanya menggunakan media sosial Instagram dan WhatsApp sebagai cara memasarkan dan memperkenalkan produk bisnisnya. Customer Relationship: Pitiks menjaga hubungan baiknya kepada konsumen dengan cara berkomunikasi secara random kepada konsumennya untuk menanyakan pelayanan dan produk yang diberikan selain itu juga Pitiks memberikan hadiah kepada konsumen yang melakukan transaksi berulang selama 6 bulan terakhir. Revenue Stream: Pitiks Roast Chicken memperoleh pendapatan terbesar dari penjualan family box roasted chicken. Pendapatan tambahan lainnya diperoleh dari layanan Preorder Makanan Asia lainya dengan tema dan konsep di luar dari Pitiks. Key Resources: sumber daya utama Pitiks adalah bumbu rahasia yang dimiliki dengan cita rasa yang dihasilkan melalui riset yang cukup lama dari pengalaman kerja chef. Key Activities: aktivitas bisnis yang dijalankan oleh Pitiks ini adalah penjualan menu utama Roast Chicken, aktivitas pemasaran, pengolah makanan, hingga mengikuti kompetisi sebagai pengalaman dalam berbisnis. Key Partnership: Pitiks sudah menjalin kerjasama sponsorship dengan salah satu club bola lokal sehingga membantu bisnis kuliner menyebarkan awareness kepada masyarakat. Cost Structure: biaya yang dikeluarkan untuk operasional adalah gaji pokok dan biaya pemasaran seperti giveaway dan sponshorship. 


\section{SARAN}

Berdasarkan kesimpulan diatas, peneliti memberikan beberapa saran yang diharapkan dapat bermanfaat bagi pengembangan Pitiks Roast Chicken.

Pitiks Roast Chicken dapat memperluas pangsa pasar hingga seluruh Indonesia dengan sistem Reseller, Frozen, maupun Perancangan Waralaba atau Franchise. Pitiks dapat mulai menjalin kerjasama dengan GoFood dan GrabFood yang menyediakan layanan penjualan makanan secara online yang nantinya dapat menambah pendapatan Pitiks. Membuat sistem ready-to eat sehingga dapat bersaing dengan kompetitor sejenis. Merancang visi misi agar dapat mengetahui goal dari bisnis kuliner ini. Mensosialisasikan Pitiks Roast Chicken dengan tema makanan sharing food dengan menggunakan bahan yang sehat di Instagram, selain sebagai makanan sharing food di Indonesia Pitiks pun perlu merancang value yang spesifik yang dapat menarik konsumen seperti membangun value makanan bergaya Internasional dengan berbahan dasar tradisonal dengan itu akan mudah diterima di kalangan masyarakat Indonesia maupun Internasional dan Pitiks pun dapat memberikan edukasi kepada konsumen tentang manfaat yang dimiliki dari rempah-rempah yang digunakan.

Pitiks Roast Chicken dapat menjalin kerjasama dengan jasa pengiriman barang yang mampu menyediakan layanan melebihi 3 boxes dengan menggunakan safety box food sehingga dapat mengurangi biaya ongkos kirim konsumen. Menyiapkan satu sumber daya manusia yang mampu mengelola Media Sosial hingga beranggung jawab me-maintain konsumen dalam membangun opini produk yang baik. Bekerjasama dengan jasa pembayaran lainnya. Disarankan untuk segera mendaftarkan Logo maupun nama bisnis kuliner pada Hak kekayaan Intelektual, menjalin kerjasama dengan Komunitas UMKM Pusat maupun Daerah untuk mendapatkan informasi- informasi terkait peningkatan bisnis kuliner hingga kompetisi. Menjalin kerjasama dengan reseller, sampai dengan menjadi partner bisnis untuk bisnis lainnya, seperti menjadi supplier bisnis kuliner lainnya. Lali, menjalin mitra dengan supplier sehingga akan mendapatkan harga yang tidak beragam.

\section{DAFTAR PUSTAKA}

Arief, A.M., (2021, June 3). Pertumbuhan Sektor Mamin 2020 Diprediksi 1-2 Persen. Bisnis.com. https://ekonomi.bisnis.com/read/20210103/257/1338004/pertumbuhan-sektormamin-2020-diprediksi-1-2-persen

Bateman, S. \& Snell, T. S. (2002). Management: Competing in The New Era. The McGrawHill.

Gürel, E. \& Tat, M. (2017). SWOT Analysis: A Theoretical Review. The Journal of International Social Research, 10(51), 994-1006.

Ginanjar, D. (2020, November, 21). Optimis Bisnis Kuliner Bertahan saat Pandemi Covid19. JawaPos.com. https://www.jawapos.com/surabaya/21/11/2020/optimistisbisnis-kuliner-bertahan-saat-pandemi-covid-19/ 
Hayden, B. (2014). Competitive Feasting Before Cultivation? A Comment on Asouti and Fuller. Current Anthropology, 55(2), 230-231. http://dx.doi.org/10.1086/675378

Husjakarsih, I., Narulita, R., Rosiadi, A., Pertiwi, R. P., Dwicahyo, M., Yanti, F., Maylani, Z., Nefriana, R. R., Nasrul, Surbakti, S. R., Heriyana, A., Prehandoko, D. S., Pazanudin, A. F., \& Ratri, W. A. M. (2020). Klasifikasi Baku Lapangan Usaha Indonesia (KLBI) 2020. Badan Pusat Statistik.

Jackson A, \& Harjanti D. (2015). Evaluasi dan perancangan model bisnis pada kaisar organizer dengan business model canvas. AGORA, 3(2), 302-309.

Kuncoro. (2009). Metode Penelitian Bisnis (2nd ed.). Penerbit Erlangga.

Lazuardi, M. \& Triady, S. M. (2015). Ekonomi Kreatif: Rencana Pengembangan Kuliner Nasional 2015-2019. PT Republik solusi.

Osterwalder, A. \& Pigneur, Y. (2010). Business Model Generation. Wiley \& Sons, Inc.

Peluang dan Kreativitas Bisnis Kuliner Meningkat di Masa Pandemi. (2020, November 6). Diakses pada April 2021 dari : https://kumparan.com/kumparanfood/peluang-dankreativitas-bisnis-kuliner-meningkat-di-masa-pandemi-1uXOjEP3bkH

Pitiks Roast Chicken. [@pitiksroastchicken]. (2021, April 18). Just Thigh! Yess for You who love Chicken's Thigh and of course, with our lovely spices rub! . DM US Or. [Photograph]. Instagram. https://www.instagram.com/p/CNzc8ubgGxA/

Pitiks Roast Chicken. [@pitiksroastchicken]. (2021, Juni 6). Happy Sunday! Hope you will have amazing day with your loved ones. DM US Or WA 081546231022 JAKARTA \#makan \#kulinerjakarta. [Photograph]. Instagram. https://www.instagram.com/p/CPwpWNCAgY-/

Pitiks Roast Chicken. [@pitiksroastchicken]. (2021, Juni 7). Yess, enjoy this Box with anyone. Family, Friends, Colleague and anyone else. . . DM US!! Or WA o81546231022 JAKARTA \#makan \#kulinerjakarta. [Photograph]. Instagram. https://www.instagram.com/p/CPoBliJA_w7/

Pitiks Roast Chicken. [@pitiksroastchicken]. (2021, Juni 10). Cheesy and savory! PITIKS PARMIGIANA . . DM US!! Or WA o81546231022 JAKARTA \#makan \#kulinerjakarta \#roastchickenforthewholehfamily \#chef \#jualayam \#coleslaw \#dinner \#makanmalam \#anakjajan. [Photograph]. Instagram. https://www.instagram.com/p/CP71uMkALbA/

Sanusi, A. (2011). Metode Penelitian Bisnis. Salemba Empat.

Sugiyono. (2016). Metode Penelitian Kuantitatif, Kualitatif, dan R\&D. Alfabeta.

Sukarli. (2017, Maret 23). Pariwisata Jadi Fokus Pembangunan Banjarmasin. ANTARA News. https://kalsel.antaranews.com/berita/44506/pariwisata- jadi-fokus 
pembangunan-banjarmasin

Yona, S. (2006). Penyusunan Studi Kasus. Jurnal Keperawatan, 10(2), 76-80. http://dx.doi.org/10.7454/jki.v10i2.177

Zulfikar, R. Mayvita, Prihatini, A. Purboyo, S. (2019) Adopsi Teknik Penyusunan Business Plan Model Canvas Untuk Perencanaan Bisnis Umkm Kuliner Jalanan Di Kawasan Gatot Subroto Banjarmasin. JURNAL PENGABDIAN AL-IKHLAS, 4(2), 171-185. http://dx.doi.org/10.31602/jpaiuniska.v4i2.1955 